lower animals. Veterinary anthorities declare that equine diphtheria is of the rarest occurrence, and only one definitely proved case was, he believed, known. That cats suffer from diphtheria seems to be a popular idea, but there is very little scientific evidence in its favour. The few cats examined by the writer (swabbings or post-mortem) always showed negative results. Birds suffer from avian diphtheria, but he believed he was correct in saying that this disease is quite distinct from human diphtheria, and not due to the Klebs Löffler bacillus. It must be remembered that bacilli, morphologically very like diphtheria bacillus, are fairly common, and mere evidence of morphological similarity is quite insufficient for proof of any etiological relationship. The main argument of his paper had really been but little assailed, i.e., that the disease is spread by infected contacts, themselves not ill. It has been completely proved that diphtheria bacilli occur in such cases, yet (excepting Dr. CaldwellSmith) those who objected to their isolation had not advanced a single argument in proof that they do not spread the disease. 'The crucial point remained, either these cases spread the disease or they do not. If the latter, let us have evidence of their harmlessness; if the former, he would repeat, it was hopelessly illogical and unscientific to isolate the case and let these persons go free to infect wherever they can. It was not possible to criticise Dr. Caldwell-Smith's experiences without more extended study of all the facts. It is obvious that the question must be elaborately studied and not merely judged by the negative evidence of absence of notified cases. Dr. Savage remarked that the severest criticisms had been levelled against the statement that the prophylactic use of antitoxin was unscientific as a preventative agency, and that it was useless to clear off the bacilli in the throats of infected cases. Nothing that had been said had made him wish to alter that statement. Its use did not prevent infection with the bacilli. As a procedure to forestall symptoms of the disease, it may have a wider utility than he was inclined to yield to it, but its usage in no way prevented the dissemination of the bacilli. It was, he believed, quite impracticable to inject all contacts with antitoxin as a routine measure. He stated that antitoxin injections were useless to remove bacilli, as the results of his own experience, the recorded experience of others, and upon theoretical grounds. Antitoxin neutralises the toxins formed by the diphtheria bacillus. 'The antitoxin is not inimical to the bacillus itself, but to its toxins, nor, as far as he was aware, does it stimulate the cells of the body to produce substances antagonistic to the bacillus. On what grounds, then, should antitoxin help to remove the bacilli? The suggestion that statistics should be prepared to show the incidence of the disease in the districts which examined contacts bacteriologically, as contrasted with those that did not, was valuable, but there were obvious difficulties, while many of these cases in the more bacteriologically protected districts were infected from contacts and cases from the rlistricts in which contacts were ignrred.

\section{DIPHTHERIA :}

BY ANDREW SMITI, M.1), Medical Officer of Health, Whickham.

$M$ $Y$ interest in diphtheria soes back to forty years ago, when I suffered from it as a schoolboy, just old enough to be (leculy interested in my own case.

1 can never forget the utter exhaustion and prostration which came on almost sucldenly on the evening of the filst day of illness, after I had tried to conceal it and kept going about. And yet the attack proved to be comparatively mild, mildness itself when compared with that of my younger brother, who was then convalescing from what had been considered a hopeless attack.

We were treated vigorously with local applications, gargles and inhalations, and both recovered completely and without subsequent paralysis.

This fact gave great encouragement at the commencement of practice, and the fact that no other cases occurred in the neighbourhood immediately before or after did not suggest great infectiveness, as but few precantions were taken.

The first cases met with in practice formed a striking contrast. A severe case of faucial diphtheria was treated most vigorously by local applications of carbolic acid and iron every two hours for many days, the applications being mostly made personally; iron and chlorate of potass were given internally, and, with careful feeding and tree use of stimulants, convalescence became established. Subsequently, paralysis came on, at first of the soft palate, but it gradually extended to the limbs and trunk, until it caused cleath by extersion to the respiratory muscles.

In the meantime, attention was drawn one day to a young child in the same family who had become prostrated. Examination disclosed that the fauces, nose, anus, and vagina -almost all the visible mucous surfaceswere covered with diphtheritic membrane. Of course, the child died of profound toxæmia.

Fortunately, such severe cases are quite exceptional, but it is none the less true that, do as we liked, we found many cases die of sheer toxamia, in spite of all treatment carried ont most assiduously; and though the cases of

* Presidential Arldress to the No:thern Branch of the Societg of Melick Officers of Health, on Uct.ber $233 \mathrm{rl}, 1908$. 
such extensive paralysis as that related are very exceptional, it is by no means uncommon to get fatalities from heart failure during convalescence, either quite suddenly or more slowly: partly from degenerative changes in the heart muscle itself, with cardiac dilatation, or from cardiac paralysis due to degenerative changes in the nerve cells. Such cases have, in my experience, been very rare, for the reason, as I believe, that $I$ have insisted on all cases of diphtheria, however mild, being kept in bed for a fortnight after convalescence was established, and only afterwards allowed the mildest exercise for a month. At the present day, with anti-toxin treatment, I still, as far as I am able, insist on this.

On the whole, during at least twenty-five years' experience before the introduction of anti-toxin, we got very good results from this thorough local treatment by antiseptics, iron and chlorate of potass internally, good feeding and stimulants. I did not allow sleep to interfere with the local treatment, because it was found that at the height of the disease if the local treatment was missed for a few hours the nembrane invariably spread. The patients were therefore roused up at the regular times, had their throats brushed, and medicine, food and stimulants given. When this treatment was commenced early enough in purely faucial cases, it was but very rarely that laryngeal symptoms developed.

I have the liberty of drawing on my brother's experience as well as my own, for we always kept in touch with each other in the management of diphtheria, and I saw some of his worst cases in the severe local epidemics which occurred in his practice.

By good results I mean that, apart from laryngeal cases, our mortality was not more than 20 or 25 per cent., and, as I have said, we but seldom got laryngeal symptoms if we got the cases under treatment before laryngeal symptoms occurred.

In pure laryngeal cases, however-the cases of so-called membranous croup-the matter was very different. Here local treatment could not be applied, and these cases almost invariably died. Whenever we found at the first visit a child with croupy symptoms, i.e., harsh breathing, ringing metallic cough, some dyspnœa, retraction of the episternal notch and intercostal spaces, and even without these latter, with membranous patches on the tonsils or any other part of the fauces, indicating membranous croup or laryngeal diphtheria, the patient almost invariably died from suffocation, in spite of all treatment, for the operation of tracheotomy, so comparatively successful in hospitals, helped us very little in colliery country practice, where efficient nursing could not be obtained.

I had only one recovery from true laryngeal diphtheria before the days of anti-toxin.

In a paper read before the Newcastle-onTyne Clinical Society, in November 1889, my brother, Dr. Smith, of Ryton, stated that out of a very considerable experience he had not had a single recovery; and this is in accordance with the extensive experience of Trousseau, who had only known six cases recover without tracheotomy.

Taking all varieties of the disease, we were fortunate indeed if we got, in a large series of cases over many years, a mortality of much under 50 per cent., and to get it much under 40 per cent. we had to use the most persistent local treatment, continued over many days, which was a severe ordeal for our patients, generally young children.

Thanks to the investigations of the bacteriologists, our position regarding diphtheria has been enormously improved. We have now not only a very complete knowledge of the disease, but we have had placed in our hands a remedy which may be truly described as an antidote or specific cure-the diphtheria anti-toxin.

Stated briefly, diphtheria is a disease due to a specific organism-the Klebs Löffer bacillus. The growth of this on the mucous membrane of the respiratory passages produces a toxin which, being absorbed into the blood, causes the symptoms of the disease. When death results, it is usually due to pure toxemia; but in laryngeal cases it is due to suffocation. owing to the specific psendo-membrane blocking the larynx, for in these cases death results before the toxæmia is itself sufficient to cause it. If death from toxæmia or suffocation be averted, further and later symptoms occur from organic changes of a degenerative character in the tissues, especially the nerve cells, which result in paralysis of a characteristic type. This may cause death from progressive paralysis ultimately affecting the respiratory muscles or more usually from heart failure.

Anti-toxin acts by neutralising the toxin, thereby aborting the disease. It has no effect 
on the toxin which has already been absorber and become firmly attached to the nerve cells. As this happens within half an hour of the absorption of the toxin, we may say that antitoxin has no effect in neutralising any toxin which has been absorbed for more than half an honr, but it will at once neutralise any that may be absorbed subsequent to its administration.

No matter how large a dose is giren it cannot do more than this. It is therefore rather preventive of further damage than curative of the damage already done.

If a lethal dose has already been absorbed, anti-toxin can do no good, death will still result. But if a lethal dose has not yet been absorbed, anti-toxin will effect a cure by preventing all further toxic effects, while the natural curative powers with what further aid we can confer will restore the injury already effected.

If, however, the amount of toxin already absorbed, though not sufficient to cause immediate death by toxemia, is still such as would cause that degree of degeneration of nerve cells, as would result in paralysis, it is equally clear that no amount of anti-toxin can avert this result.

No matter how large a dose is administered, the paralysis will follow.

When we realise what a mnit of anti-toxin means, and when we further realise that it cannot neutralise any toxin already absorbed and fixed, but can only abort the disease at the stage at which it is administered and prevent further toxemia, it wonld seem that no very heroic dose should be necessary.

Such is the teaching of the experimental bacteriologists, and when this is tested by clinical experience it is found to be absolutely true.

Immediately after being appointed medical officer of health for the Whickham Urban District, the Council on my advice decided to supply anti-toxin gratuitously, and all doctors practising in the district were duly notified of the fact with a strong representation of its value. Since then it has been very generally though not invariably used. One still hears expressions of doubt as to its utility, and there is still a tendency to defer its administration until other means have been tried, which is surely a very great mistake. Used in this way as a last resort, when death is already imminent, it is not of the slightest value either in toxæenic or laryngeal cases; hence where it has only been thus used one can understand the scepticism as to its value.

During the four-and-a-half years of which I have the records, there have been notified 120 cases with 12 (leaths, which gires a case mortality of exactly 10 per cent.

This is a great improvement on the 40 or 50 per cent. mortality prior to the introduction of anti-toxin, but it does not give at all an arlequate expression of the value of the remedy, for it takes no account of the rapidity of recovery nor of the great relief of suffering so quickly given and the non necessity of severe local measures, and on analysing and enquiring. into the deaths it was found that in several cases anti-toxin was not used at all, and in others it was only used when too late to be of any benefit: at least nine of the twelve were either essentially laryngeal cases or they had laryngeal symptoms before anti-toxin was used. In some returned as membranous croup, the diphtheritic nature of the disease was scarcely recognised, and I am not prepared to say that they must all have been diphtheritic; for although I believe it is a safe rule to regard all cases of laryngitis with marked obstruction as most probably diphtheritic, and as consequently indicating the use of anti-toxin, there are good grounds for believing that fatal laryngitis, even fatal membranous laryngitis, may occur independently of diphtheria and these will not be favoutrably influenced by anti-toxin. Ono case I know had been ill a whole week, and laryngeal symptoms had existed two days before anti-toxin was given, and it is not surprising that death resulted a few hours later. In two of my own cases laryngeal obstruction was so severe when first seen that I only gave anti-toxin as a chance, but with little hope of success as tracheotomy was declined.

In another case of my own, symptoms had existed for a week before $I$ saw it, the parents having litherto trusted to repeated blowing of sulphur into the throat. The fauces, pharynx, and solt palate were thickly covered with nembrane, and the whole throat looked grangrenons, and the fetid odour of the breath made the room sickening. The child was dying of toxic poisoning from malignant diphtheria; though I gave anti-toxin as a routine, it was without any hope, and the child died the same night. 
In striking contrast was the sister of this child, who took ill during the night a few days later. When $\mathrm{I}$ saw it in the morning the tonsils, uvula, and soft palate were already covered with membrane. A dose of anti-toxin of 2,000 units was at once injected, the further progress of the disease was arrested, and in forty-eight hours every trace of membrane had disappeared and the ehild was convalescent, and no paralysis followed.

This is my almost invariable experience in faucial diphtheria. With the above exception, I have not during these years had a death from immediate toxæmia, nor from laryngeal obstruction where the larynx was not already invaded when first seen.

I make it a rule never to go a driving round without a sterile swab and a few doses of anti-toxin in my bag. In every case of diphtheria, or where the condition is strongly suggestive of diphtheria, I take a swab and at the same time give 2,000 units of anti-toxin, and invariably by the time I get a report, which in these cases is nearly always positive, the patient is convalescent. I scarcely ever give a second dose, and I do not believe it is ever necessary.

In laryngeal cases the position is somewhat different. If the symptoms are still mild, indicating only slight obstruction, the result is equally satisfactory, as the disease is quickly arrested; but if there are inclications of severe obstruction, and this has come on quickly, then, by virtue of the very efficacy of the treatment, the symptoms are liable to be aggravated and the immediate danger increased, because as the membrane loosens in bulk it only further obstructs the breathing; and as the most violent inspiratory efforts are being made, the mass of membrane is liable to be sucked into the trachea and bronchi. I have in some cases met this with success by having an emetic dose of Vin. Ipecac. ready to be gicen whenever the obstructive symptoms become markedly aggravated, as the immediate act of vomiting forces up the loosened membrane. In most of such cases, however, I firmly believe that tracheotomy is indicated and should be performed. With anti-toxin already administered, the operation, unless too long deferred, adds but little to the danger, at least, if skilled nursing can be procured. In country and colliery districts this onght to be considered indispensable.

At the same time, I have during the last two years seen a consiclerable number of laryngeal cases, some of them very severe, in which by the immecliate use of anti-toxin, the stean kettle, and Vin. Ipecac. used as above stated, all but one have recovered without tracheotomy. The fatal case was a clinld aged. three years, who took ill during the night with symptoms of croup; was seen in the morning, when anti-toxin was given, and arrangements made for tracheotomy, but when this was performed within two hours by an expert operating surgeon, the child was already in extremis and it never rallied. Such a rapidly fatal case as this baffles all treatment. Fortunately such cases are rare.

We may say with perfect confidence that the essertial, the only real treatment of diphtheria, is anti-toxin.

When administered properly and sufficiently early it is in all but a very few cases, certain, speedy and complete, all other treatment is but supplementary. When administered early enough, one dose of $2,000 \mathrm{mnits}$ is nearly always sufficient. In late cisses I have sometimes given more-up to 6,000 units-but I honestly believe that these larger doses were unnecessary, and certainly no results could be better in the great majority of cases which I have treated than that obtained by a single dose of 2,000 units.

How anyone who has had experience of cliphtheria in the days before anti-toxin was introduced, and who has watched the progress of cases since, when this remedy has been systematically used, can for a moment hesitate to use it, or can even reconcile it with his conscience to postpone its use for evelr an hour, is what I cannot understand.

It never does any real harm; it is true that in a certain proportion of cases, joint pains, generally of a trifling character, result from the serum, and in abont 5 per cent. of the cases an irritable erythema or urticaria results from the same cause ten days or a fortnight after its use, but they soon pass off, and surely this is only a small price to pay for the speedy and effectual cure of such a malignant disease.

An idea has become somewhat prevalent that it increases the tendency to paralysis, but this is a pure delusion without a scrap of evidence to support it.

It is quito true that some statistics have shown an increased number of cases of diphtheritic paralysis since anti-toxin was 
used, but that is only because so many more cases have recovered, and we know that the remedy has no effect on the toxin which had already been absorbed prior to its use. It is that previonsly absorbed toxin which causes the paralysis, and, therefore, the way to prevent paralysis is to use antitoxin enty.

In my experience paralysis very rarely occurs when anti-toxin has been used on the first or second day, but it is common enough when its use has been deferred just as it was in former days when anti-toxin was unknown. Anti-toxin has never caused paralysis in laboratory experimental animals, and the horses used for its production, and whose blood becomes saturated with it, never develop paralysis.

At first the expense of anti-toxin rather militated against its nse when very large doses were considered necessary; but if my experience with the smaller doses given early is at all in accordance with that of others, this no longer holds, for that dose only costs $2 \mathrm{~s}$. $6 \mathrm{~d}$., considerably less than what in former days was spent on brandy and other alcoholic stimulants which are now but seldom required.

Besides, the most liberal and advanced councils now supply the remedy gratuitously, and in doing this they act with the truest economy, not only in the saving of life and suffering by encouraging its use at the earliest moment, but the initial cost is saved many times over in lessened hospital expenditure.

\section{Local Treatment.}

With the use of anti-toxin, local treatment to the throat has, in my opinion, become quite unnecessary. Where the patient is old enough and is not nervous, mild sprays, gargles, or the local application of mild antiseptics may be helpful, and may be found soothing; but when, as is most frequently the case, the patients are young nervous children, I am confident that they do more harm than good. They interfere with the all-essential rest, and cause a degree of unnecessary excitement which may even be dangerous when the heart is showing signs of failing. I make this statement in spite of the fact that in. former days we got excellent results from persistent local treatment, and indeed almost wholly relied on it.

Whether the frequent application of power- ful antiseptics to the throat diminishes, to an appreciable extent, the infectiveness may be more open to question.

It is quite certain that we cannot destroy all the bacilli by this means; we can only deal with a small area leaving a much larger one where the bacilli still lurk quite unaffected. But as it is necessary to isolate the patient for a prolonged period in any case, I do not believe that such local applications do any good at all, certainly nothing in comparison to the suffering and shock which they cause to the majority of our little nervous patients.

In laryngeal cases I still use the steam kettle charged with a little sanitas.

It is much the same witld drugs. I generally give an iron mixture with chlorate of potash or liq. ammonice acetatis at the beginning, and iron and strychnine or nux vomica during convalescence, and I believe they do good, though in average cases treated early by anti-toxin they are probably not essential. With regard to the first especially, no great importance can be attached to it in genuine cases, but as it is most valuable in septic throats which the most resemble diphtheria, it is generally worth giving. In true cases aborted early by anti-toxin before there has been much toxic absorption, convalescence is generally uninterrupted; but in later cases iron and strychnine are most valuable in convalescence and may almost be regarded as necessary where there has been much toxic absorption. Fiach case must, however, from clay to day be treated individually. It is not so much the specific disease as the patient who requires drug treatment, so that the general condition must receive the utmost attention, especially the heart and nervous system. Here the great guide is the condition of the pulse; wherever there is irregularity, low tension, excessive quickness or undue slowness, there is indicated the need of strychnine, as there is also when other symptoms of paralysis manifest themselves. Full nourishment throughout is essential, taking care to give only what is ensily digested and absorbed, which does not overload the stomach, produce flatulent distention and throw too much work on the kidneys.

As regards stimulants, in former days we found it necessary to give them very freely; nor-a-rlays it is but seldon that I preseribe them at all. Again, the pulse and general condition are the guides. My younger brother, 
only aged seven years, took for a week on an average two bottles of port wine in three days, and one day he had a whole bottle without any apparent intoxicating effect. I was not considered ill enough to get any. These facts show to me that the old country practitioner, for he was an old man who attended us; was a very wise and careful practitioner.

\section{Anti-toxin as a Prophylatid.}

Should anti-toxin be used as a prophylactic? In my opinion this is seldom necessary or advisable. Though it is common enough for one or more members of a family to contract the disease after the occurrence of one case, this cannot be said to be the rule. Unquestionably a prophylactic dose would effectually protect all those others for three weeks or so, but, after all, only a small proportion would develop the disease without this prophylactic, especially if the first case was promptly isolated, as we all agree is necessary. But it would not prevent contacts becoming "carriers," because we know that the insusceptible, whether immune naturally or artificially, can harbour the bacilli in therr respiratory passages and so convey infection to others.

It would, therefore, be no gain to public health, and a certain proportion of those who get the prophylactic dose would have the disagreeable effects in urticaria, erythema, and arthritic pains. On the other hand, if they $\mathrm{nr}$ the parents are cautioned to be on the alert, on the earliest symptoms of the disease occurring, a curative dose can be given with the certainty of at once arresting the disease, and this surely ought to be sufficient.

The only case in which I think a prophylactic dose is advisable, is where a patient has been admitted to the diphtheria ward of an infectious disease hospital on a wrong diagnosis. Here he is exposed to an unnecessary risk which a prophylactic dose of anti-toxin would at once remove and he might be discharged at once.

With the treatment of diphtheria by the early administration of anti-toxin, I feel confident that the mortality may be reduced almost to the vanishing point, especially if the public can be taught to seek medical advice early in all cases of sore throat, and especially on the occurrence of croupy symptoms. The mortality ought to be reduced considerably below that of the hospitals where the cases are too often only sent in a late stage of the disease, and often-by far too of ten---without the previous administration of anti-toxin.

Excellent as are the provisions made for notification anrl subsequent removal to hospital, and for bacteriological examination by an expert, they have serious disadrantages, inasmuch as they discourage immediate treat= ment by the general practitioner. Of this fact I lave abundant evidence.

To defer administering anti-toxin in a reasonably suspicions case is wrong. It is wrong to trust to its administration in hospital and it is wrong to wait for bacteriological confirmation, for in country districts each of these delays means a loss of two days.

I do not think that even in early and mild cases the clinical diagnosis is nearly so difficult as is generally stated and, valuable as the bacteriological confirmation is, my personal experience has been that for practical purposes the bacteriological diagnosis has been more at fault than the clinical." On the latter I have always acted.

An amount of dogmatism is here quite justifiable. Whenever a case is doubtful a swab shonld be taken and examined; but whenever there is a reasonable suspicion of diphtheria anti-toxin should be given at once; and if the case cannot be properly isolated at home, hospital isolation should be advised and urged.

The general practitioner should not hesitate to risk a wrong diagnosis in the interest of his patient, but he should at once communicate the bacteriological report to the hospital physician. If the report be positive, he will already have cured his patient, if negative he will have saved him from all risk of infection in the diphtheria ward.

The hospital physician should then have another swab examined, and if still negative he can safely discharge the patient.

In a case like this where every hour counts, as it most certainly does, it is infinitely better to give an occasional unnecessary dose of anti-toxin, than to jeopardise life by delay, for it is doubtful if the remedy has any effect after the fifth day.

The importance and urgency of the case would seem to justify a special representation from the county medical officers of health to all doctors practising within their respective counties.

It is also imperative that, as in the large isolation hospitals of the towns, the doctor 
for the country hospitals should make provision for the immediate performance of tracheotomy whenever required.

I have not been able to liscover any evidence in favour of the contention of some sceptics of the anti-toxin treatment that the diphtheria of to-day is of a less malignant type than that of the past. We certainly see fewer very malignant cases, but that is because by the early use of anti-toxin we prevent the most malignant symptoms developing. Where this remedy has not been used early, we still get the old malignant type, and I have seen numerous cases of extreme severity of only two or three days duration immediately arrested by a single dose of 2,000 units.

I have seen more cases of pharyngolaryngeal diphtheria during the last two year's than ever I saw before in the same time, and all have recovered under anti-toxin without tracheotomy, while in the old days practically all such cases died.

I do not therefore believe that there has been any lowering of the virility of the infection.' The improvement has alone been due to anti-toxin, as have also been the greatly improved hospital statistics.

Where in private practice this remedy has not been generally and early used, the case mortality has remained high; where it has been systematically used the mortality has been greatly lowered. The evidence of Dr. Taylor, in his annual report for 1906, is most valuable on this matter. In a large area with many townships, the ease mortality was proportional to the supply of anti-toxin; where it was largely used the mcrtality was low; where scarcely or not at all it was as high as in the old days. I do not agree with what Dr. Taylor says in that report with regard to dosage, for he recommends large and repeated doses ; but I most thoroughly agree as to the necessity of its early administration. It is not so much the size of the dose (within certain limits, of course) as the earliness of its administration which is the essential matter.

\section{Prevention of Diphtheria.}

When considering the prevention of diphtheria we must be guided entirely by the knowledge we possess as to its origin and mode of spread.

The only facts clearly proved are direct and indirect infection, direct from patient to patient, indirect through intermediate carriers who, though not themselves ill, harbour the bacilli in their respiratory passages and infection through drinking ressels, milk, etc., contaminated by patients, convalescents and contact-carriers.

All other alleged methods of origin must now be regarded as doubtful and unproved, such as general and special insanitary conditions, defective and obstructed drains, cesspools, manure heaps close to dwellings, damp and mouldy walls in dwelling-houses, recent disturbance of soil as occurs when new houses are built, etc. At the same time, I am not prepared to admit that these various conditions play no part in causation.

The immense amount of evidence accumum lated in favour of the association of diphtheria with such conditions should not be lightly ignored. I am sure we have all seen-I certainly have seen-numerous cases in which this association was present, and where it was impossible to prove direct infection.

We all may admit that these conditions do not originate diphtheria, and yet believe that they in some way favour the development of the disease when the bacilli are otherwise introduced.

I am not satisfied that the mere lowering of vitality caused by these conditions is a sufficient explanation of the association; there is something specific and definite about it that we do not yet understand.

It is true that all this evidence suffers from lack of mathematical precision, but that cannot be said of the investigations of Newsholme on the endemic and epidemic prevalence in different countries, on the comparative incidence in rural and urban areas, on seasonal prevalence, on influence of soil and climate, and on the incidence of the disease compared with rainfall and level of ground water, for these investigations have been conducted with mathematical precision throughout.

It seems to me to be quite certain that in diphtheria and in all the other infectious diseases, it is not enough to know the specific bacillus which causes the disease, to know its life history and how it affects the body; there are other factors almost equally important in the body itself which cause varying degrees of susceptibility and which modify the action of the bacilli and their toxins; hosts of conditions of which we are still ignorant, and which will only be fully elucidated by the association of mathematics with observation, experiment and induction. 
There are at the one extreme the significant investigations of Hamilton, on braxy and lonping ill in sheep, showing the extraordinary seasonal infuence as regards susceptibility aur immunity while the bacillary culture remains the same; then in diphtheria, and perhaps pneumonia and tuberculosis, the very variable susceptibility both in individuals at any time and the same individuals at different times going on to such diseases as small-pox and measles, where apparently everyone is susceptible at all times until one attack has been gone through, and even then there is still apparently a seasonal prevalence.

As regards alleged infection from a similar disease in domestic animals, snch as cats and fowls kept in backyards, I think we may say that this also is unproven; but until many more investigations have been made into the alleged diphtheria of animals, we cannot say that it is altogether disproved.

As medical officers of health, I am sure we only act wisely when we enquire into all these possibilities and insist on all insanitary defects being remedied, and when we make the occurrence of an outbreak of diphtheria the occasion of effecting sanitary reforms.

After that we must face the essential problem of dealing with infection by direct and indirect contact.

The facts are, first, infection from the patient, not only during the attack, but for an indefinite and prolonged period afterwarts. Second, probable infection by all contacts, also for a prolonged period.

Third, the only proof of infectiveness is the culture of diphtheria bacilli from swabs taken from the throat and other respiratory passages.

Whenever a swab taken from the throat gives a positive result, the person from whom it is taken is an infective subject and a danger to the community, and he should accordingly be isolated.

The logical outcome of this is that all diphtheria patients should be isolated until repeated swabs are proved negative, and that all contacts should be similarly examined and isolated so long as swabs from their throats give a positive result.

So, also, when the medium of infection is clearly or even probably a school, all the children, or at least those in the probably infected class-room should be similarly dealt with.
All this would, however, involve an intolerable interference with personal liberty, and there would still be the difficulty of deciding upon who should carry it ont.

Browning's Bishop Blougram gives expression to excellent wisdom in words which are very applicable to the problem we are discussing. He says :--

\footnotetext{
"The common problem, yours, mine, everyone's,

Is - not to fancy what were fair in life

Provided it could be--, but, finding first

What may be, then fincl how to make it fair

$\mathrm{U}_{p}$ to our means : a very different thing !"
}

Truly a very different thing; we have got to realise how far we can safely go, and then determine how we can best act within that limit.

It seems to me that the best and simplest method would be to concentrate attention on the children, and act through the education authority by getting the following rules enacted: First, no child notified as suffering from diphtheria will be re-admitted to school until a certificate is received that a bacteriological examination has been made and found negative.

Second, that all other children in the infected house (even if the patient has been removed to hospital) shall be excluded until they ean produce a similar certificate.

Third, where there is good reason to believe that a school is the centre of infection of a group or groups of cases, it may become necessary to undertake a thorough examination of the school or of one or more class-rooms where these seem to be the centres affected; and for this, co-operation between the education authority and the sanitary authority would be advisable. It could be arranged between the school medical inspector and district medical officer of health, with the assistance, if necessary, of the county medical officer of health. As the alternative to this would be school closure for a prolonged period, which is always objectionable and to be avoided unless absolutely necessary, I do not think that any serious objections would ever arise.

Fourth, bearing in mind the possibility of infection through drinking vessels, I think it may also be impressed on all school authorities that the utmost cleanliness and nicety of manners in the use of drinking vessels and in other ways should be enforced at school. This in any case would always be a valuable lesson in domestic hygiene, 
In this way, it seems to me, wust of the difficulties would be orercome. It will be noted that by the first two rules the onus of proving freedom of infection would be placed on the parents, who would naturally call in their own doctor and remunerate him in the usual way. In colliery contract practice the practitioner might feel aggrieved, but he would be more than compensated by the decreased number of cases he would have to attend, the lessened period of attention to each where anti-toxin is used, and the saving in cost of anti-toxin where that is given gratuitously by the district councils.

In the further regulations concerning the schools, the duty is only a part of what ought to be involved in medical inspection in association with sanitary administration.

The probabilities of the adult members of a household, where an attack has occurred, communicating the disease as carriers are so slight that for all practical purposes they may be ignored. The risk is slight in comparison to the grievance which would be caused by isolation and prohibition of work.

Unless it be true that the diphtheria organism has a preliminary and saprophytic existence in the soil, as is confidently alleged by some, but of which there is as yet no proof, it seems to me that by an energetic use of those means which I have briefly sketched, the incidence of diphtheria may be almost reduced to vanishing point, and by the early use of anti-toxin in comparatively small doses in the remaining occasional cases the mortality might almost cease, so that this dread disease may, in the inmediate future, in this country at least, become like cholera and typhus fever, only of historic interest, a consummation devoutly to be wished.

Minwives Act Commrtee. - The fourth meeting of the departmental committee appointed by the Lord President of the Council to consider the working of the Midwives Act was held on February 17 th at the Privy Council Office, Mr. Almeric W. FitzRoy presiding. The following witnesses attended and gave evidence: Miss Wilson, President of the Incorporated Midwives Institute; Mr. F. B. Harris, Deputy Town Clerk of Nottingham, on behalf of the Association of Municipal Corporations; Mr. Joseph Brown, of Dewsbury, on behalf of the Association of Poor Law Unions in England and Wales; and Mrs. Wallace Bruce, on behalf of the Association for Promoting the Training and Supply of Midwives.

\section{DRAINS $\Lambda$ NI) DIPH'THERI $A$.}

BY A. E. THOHAS, B.A., M.B., D.P.H., Nedical Officer of Healtli, Chester.

$T$ HE popular association of diphtheria with defective drainage is of time-honomerl, almost paleolithic antiquity, revered alike in the creed of the man on the kerb-stome, the sapient law-giver, and the writer of standard text books.

It might assurefly date from the time of the caveman, when any mishap, which could not reasonably be assigned to the unantlorised use of an illieit flint was attributed to dire omens, to drains, or perhaps, the lack of drains.

Of its truth, mntil recent times, all appeared to be convinced; few there wore who desired evidence or confirmation of the proof. For, in sooth, some one har said it: that ended the matter.

And the belief that these two factors stand in relation of cause and effect, forms the hasis of so many actions at law that, in these days of doubt and apprehension, it becomes necessary once more to review the evidence connecting them and the opinions concerning them.

With the discorery of the specific bacillus, this popular, banal and presumably camsal association, derived from preconceived and airy impressions has tended to sink into the background, and the opinions now expressed are far less dogmatic and assertire than in former days.

Thus :--

"Drainage Effluvia.-Diphtheria is more severe and more prevalent among persons exposed to foul gases from sewers or drains. The relation is, however, by no means direct. Houses with the worst forms of drainage defects may remain free from diphtheria for indefinite periods, and many cases of diphtheria occur in premises in which no defect can be found. The same may be said of other insanitary conditions, notably dampness of house, accumulations of manure and other filth in proximity to houses. All these ought probably to be regarded as predisposing causes only."-Whitelegge and Newman, 1905, p. 364.

"It has been a matter of obserration that certain rural districts in which the surface soil is cold and humid, and where damp houses and privy and drainage nuisances abound .... are particularly favoured by diphtheria."

"Faulty sanitary surroundings (drainage and filth nuisances) tend to the production of diphtheria

A paper read before the North Western Branch of the Societs of Medical Officers of Health on June 19th, 1908 , 